\title{
Modelling and Calibration of a Thermal Model for an Automotive Cabin using HumanComfort Library
}

\author{
Stefan Wischhusen \\ XRG Simulation $\mathrm{GmbH}$ \\ Harburger Schlossstraße 6-12, 21079 Hamburg, Germany \\ wischhusen@xrg-simulation.de
}

\begin{abstract}
This article aims to describe a modular system level modeling approach for the thermal behavior of an automotive cabin. The model is parameterized with geometric and physical data. At the end a set of 6 parameters is used to calibrate the model with two measurement data sets: one for a passive heat up and active pull down and one for a cold heat up. The procedure can be used as a recipe for developing own models of the same kind which may be used in integrated thermal management studies.
\end{abstract}

Keywords: automotive cabin; calibration; thermal simulation; air conditioning; integrated thermal management

\section{Introduction}

The assessment of the thermal behavior of an automotive cabin as a part of the whole vehicle becomes more and more important while the air conditioning system is not just responsible to cool and heat the passenger compartment but also has to condition other sensitive parts. Alternative, energy-saving vehicle concepts require innovative concepts to manage multiple heating and cooling loads. This has to be achieved by thoroughly optimizing many factors: e.g., energy consumption, component utilization as well as life-time reduction and last but not least passenger comfort.

Simulation models are required to allow a systemwide analysis on a conceptual level. The Modelica technology offers a multi-domain platform which allows users to combine different physical systems in order to predict their interaction. Such a configuration is for instance given by a combination of air conditioning cycle, air distribution system and cabin.
Automotive air conditioning cycles were modeled using Modelica since 2000 using different free and commercial libraries (ThermoFlow, ThermoFluid, ACLib [2], AirConditioning [3] and TIL by TLKThermo GmbH). The AirConditioning library is used by many European companies since 2004 and has become a standard tool for German automotive companies. In order to model the interaction between the vapor compression cycle and the cabin a modular and flexible model for the cabin was missing, though. Therefore, XRG Simulation decided to develop such an approach in the EuroSysLib-D project [1] which is provided by the resulting HumanComfort library. This model can be directly connected to open Modelica.Fluid air distribution models or to the AirConditiong library (version 1.8 and higher).

Tools for the thermal simulation of automotive cabins are THESEUS-FE [4], EXA PowerFLOW and PowerTHERM, which use CFD approaches for their models. Those models easily count up to some 10.000 nodes in order to capture the complex interior geometry and the required grid size for transient simulations. A coupling of CFD cabin models to air cycle models is possible by using simulator interfaces like TISC by TLK-Thermo GmbH.

Other system level models were developed by: IFT/TLK-Thermo [5], Baumgart et al. [6], Mezrhab [7] and others. The Modelica model of IFT/TLKThermo works with a single air volume and multiple walls and windows. Moreover, the cabin model of Baumgart is using multiple volumes and irradiating numbers for its surfaces.

\section{Physical Cabin Modeling}

The HumanComfort library[1] enables very flexible modular layouts for modeling physical effects. Any 
HumanComfort automotive cabin model may integrate the following physical entities in arbitrary numbers:

- Partitions (opaque or transparent) for multilayer wall setups

- Air volumes

- Air exchange models and/or flow models

- Internal load models (e.g., passengers, waste heat)

- Irradiation balance models

- Internal surfaces

- Thermal comfort models

- External boundary conditions (e.g., climate, air leakage)

The following physical effects are modeled by the component models of the library:

- Heat transfer by convection

- Heat transfer by conduction

- Heat transfer by direct and diffuse irradiation, distinction between short wave and long wave irradiance

- Convective mass transfer

- Condensation of moisture

- Carbon dioxide emission and balance for recirculation air controls and wall layers depends on the desired resolution for temperature (and other states). Focusing on air temperatures the following layouts are appropriate:

- Single air volume for pure convective driven simulations (e.g. during air conditioning operation)

- 2 air volumes in top/bottom layout if a preconditioning of the cabin during which the AC system is switched off has to be simulated

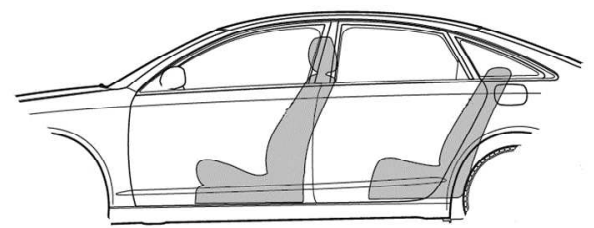

Fig. 2 Automotive cabin layout

A single air volume approach for a very popular middle class sedan car (Fig. 2) is shown in Fig. 1. The model consists of external wall partitions that are exposed to external boundary conditions on the outside for the ceiling, the floor, the left side wall, the right side wall and two smaller parts for the left and right opaque top hull part. Windows are divided into windscreen, two side windows left, two side windows right and rear window. Furthermore, inter-

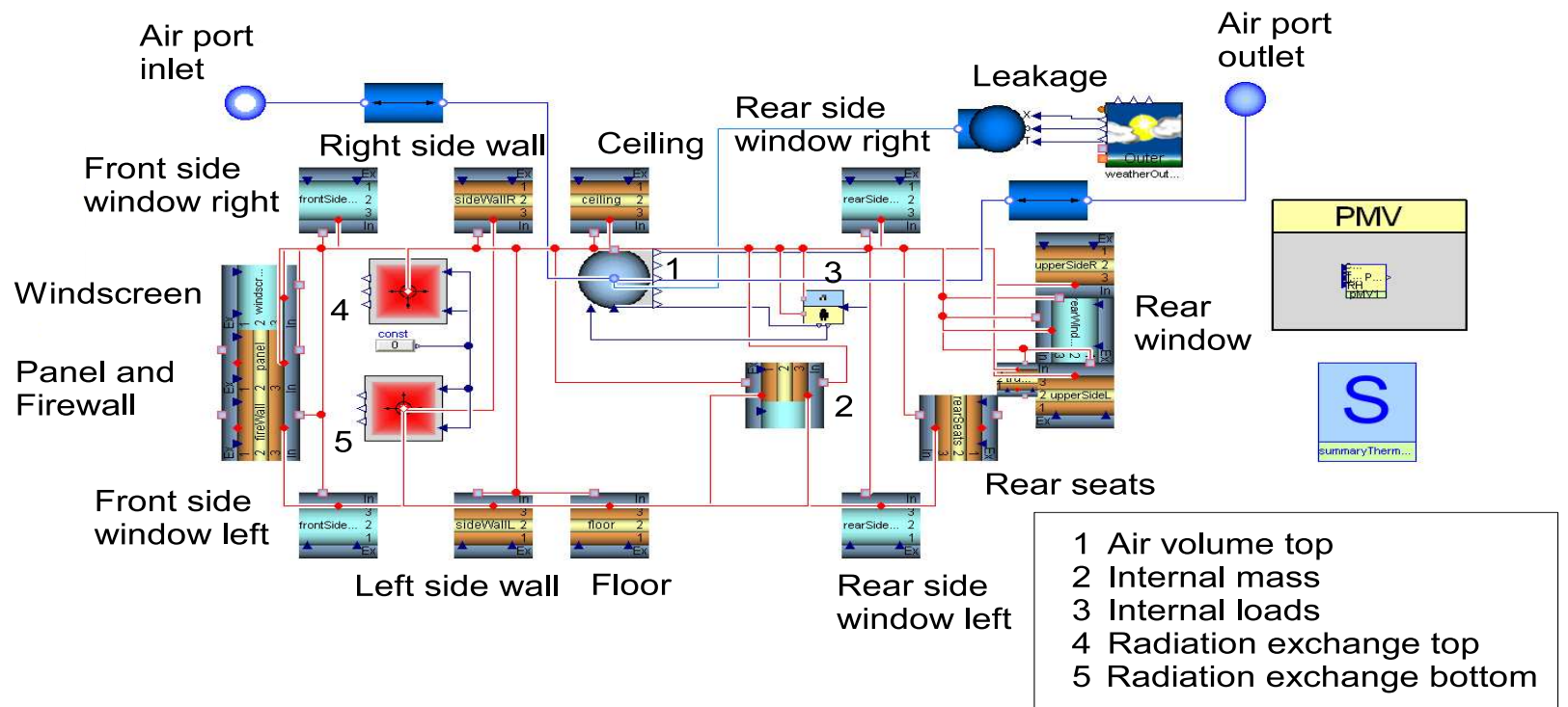

Fig. 1 HumanComfort Modelica cabin model - Single volume approach

The assessment of parameters starts with geometrical parameters. The required discretization of the cabin model with regard to number of air volumes, walls nal surfaces were integrated for the panel, the firewall, two front seats, the rear bench and trunk shelf. 


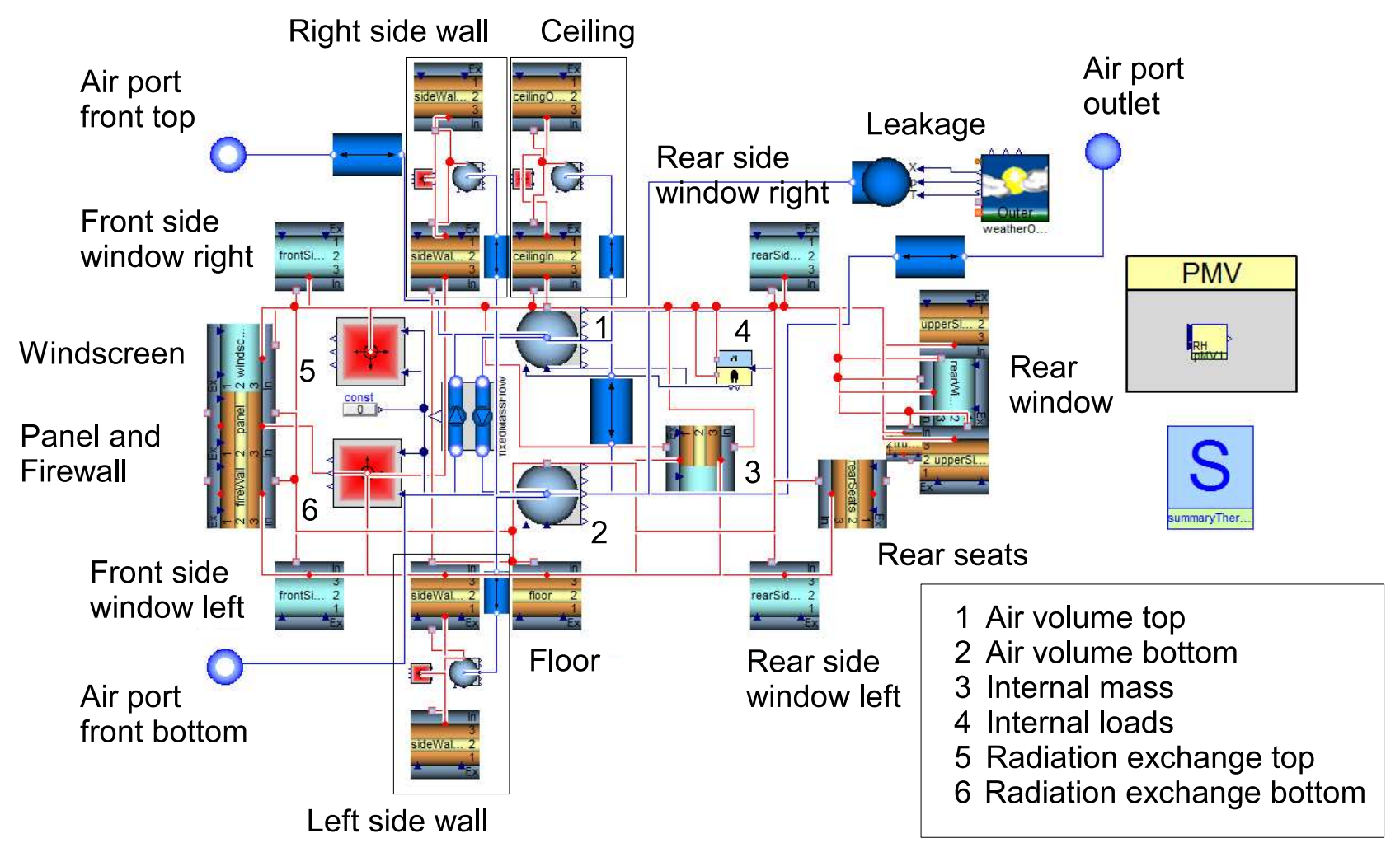

Fig. 3 HumanComfort Modelica cabin model - 2 air volume approach

Since only a single air volume is considered the air distribution modeling is very simple. A single design inlet and a single design outlet were integrated. Please note that a more complex distribution requires additional volumes and flow models that calculate mass flow rates between nodes. Nevertheless, even the single volume approach can be easily extended by more inlets and outlets (see Fig. 3), if required by the measurement setup since the fluid flow connector is according to Modelica.Fluid specification including the stream connector concept.

The 2-volume approach shown in Fig. 3 was created starting from the single volume approach. The upper volume is displaying the air state in the head area of the car. The bottom volume is standing for the average air state in the space below the windowed cabin area. Thus, the convective heat transfer connections of the walls have to consider the location of the partition (top or bottom). The convective heat transfer connectors are represented by the red and gray connectors while the radiation connectors are full red in Fig. 1 and Fig. 3. Additional elements are required for the flow exchange between the top and the bottom volume. For demonstration reasons air spaces have been integrated into the ceiling and side walls in order to simulate air temperatures here as well.
A partition is modeled as a flat but inclined wall with one-dimensional parameters. It may consist of up to 9 layers with independent properties. The outer heat transfer is due to irradiance and convective heat transfer. Optional one can also determine a heatedlayer for wall heating (e.g. for seat heating). Fig. 4 explains how geometry parameters are specified. The azimuth angle of a wall describes the horizontal direction of the outside, ambient surface normal. A south bound direction is defined to have an angle of $0^{\circ}$. Furthermore, the user has to specify the tilt angle (or zenith angle) between horizontal plain and the walls surfaces. If the zenith angle is $0^{\circ}$ or $180^{\circ}$ the azimuth angle is meaningless. For surfaces with significant curvature it is straightforward to separate the wall section into parallel partition models.

It is usually not easy to determine properties of the multi-layered cabin walls. Another challenge is defined by the later calibration of the cabin model since the physical parameters of each layer are potentially uncertain. Therefore, it may be a better approach to calculate average properties for a compound of materials and calibrate three property parameters for a wall. 

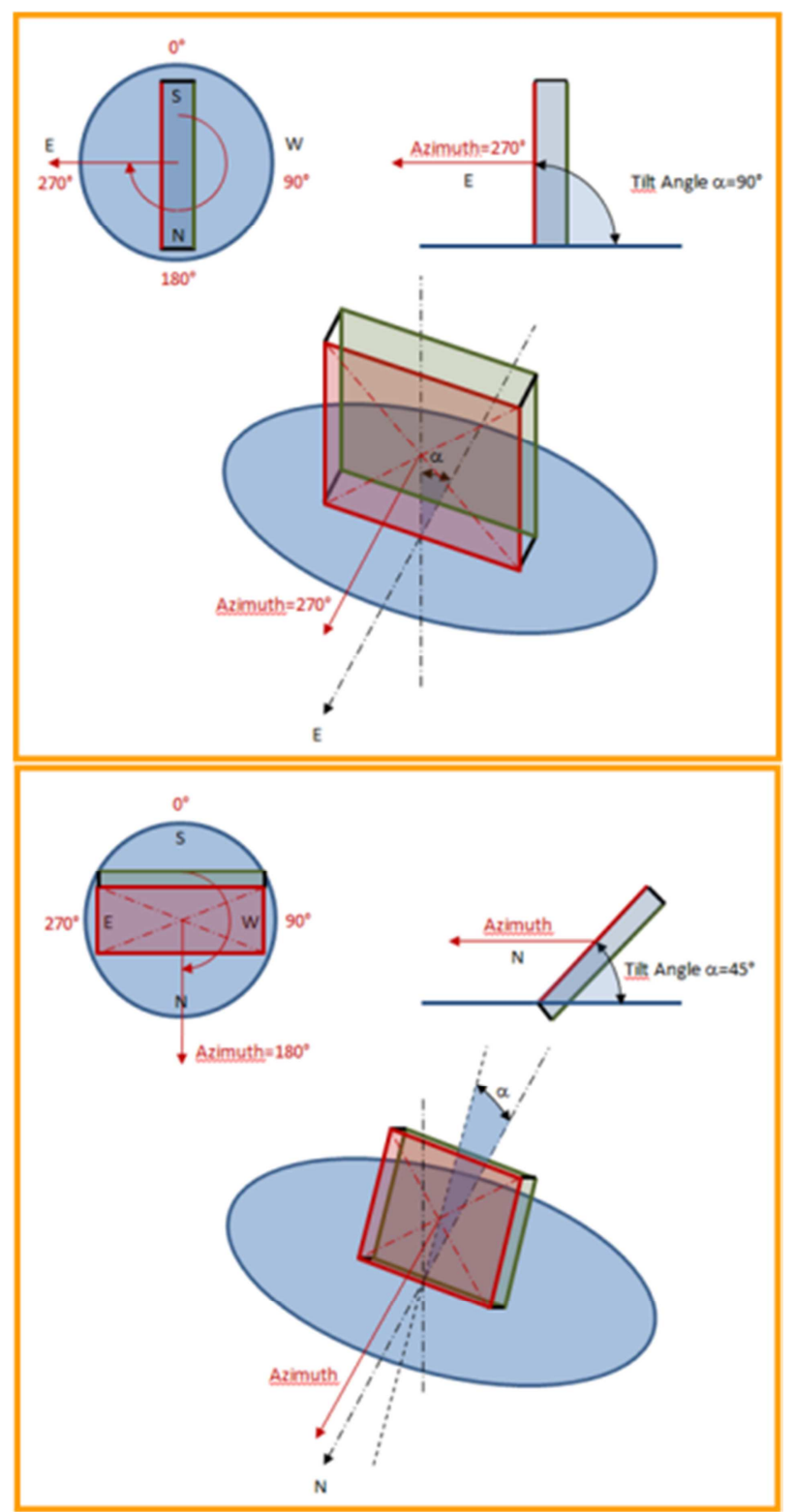

Fig. 4 Partition model orientation parameterization

The average heat capacity can be found by:

$$
c_{\text {avg }}=\frac{\sum c_{i} \cdot M_{i}}{\sum M_{i}}
$$

with

$\mathrm{c}_{\text {avg }}$ average heat capacity [J/(kg.K)]

$\mathrm{c}_{\mathrm{i}}$ specific heat capacity for material fraction $[\mathrm{J} /(\mathrm{kg} . \mathrm{K})]$

$\mathrm{M}_{\mathrm{i}}$ mass of material fraction $[\mathrm{kg}]$

The average density with respect to thermal behavior follows from:

$$
\rho_{\text {avg }}=\frac{\sum M_{i}}{V_{t o t}}
$$

with

$\rho_{\text {avg }}$ average density $\left[\mathrm{kg} / \mathrm{m}^{3}\right]$

$\mathrm{V}_{\text {tot }}$ total volume of compound $\left[\mathrm{m}^{3}\right]$

The average thickness of the compound in the sense of heat conduction is defined by:

$$
s_{\text {avg }}=\frac{V_{t o t}}{A_{H T}}
$$

with

$S_{\text {avg }}$ average thickness of compound [m]

$\mathrm{A}_{\mathrm{HT}}$ projected heat transferring area $\left[\mathrm{m}^{2}\right]$

In order to determine the average heat conductivity of a compound one can choose from two approaches that will be detailed subsequently.

Approach 1 "ideal one-dimensional layers"

$$
\lambda_{\text {avg }}=\left(\frac{1}{\sum \frac{S_{i}}{\lambda_{i}}}\right) \cdot s_{t o t}
$$

with

$\lambda_{\text {avg }}$ average heat conductivity [W/(m.K)]

$\lambda_{\mathrm{i}}$ heat conductivity of material fraction $[\mathrm{W} /(\mathrm{m} . \mathrm{K})]$

$\mathrm{s}_{\mathrm{i}}$ average thickness of one ideal layer [m]

$\mathrm{s}_{\text {tot }}$ total thickness of compound [m]

\section{Approach 2 "measurement"}

$$
\lambda_{\text {avg }}=\frac{\dot{Q}_{o i}}{A_{H T} \cdot\left(T_{o}-T_{i}\right)} \cdot s_{a v g}
$$

with

$\dot{Q}_{\text {oi }}$ heat flow rate from outside to inside [W] 
$\mathrm{T}_{\mathrm{i}} \quad$ Average inside surface temperature [K]

$\mathrm{T}_{\mathrm{o}} \quad$ Average surface temperature on outside $[\mathrm{K}]$

It has to be pointed out that the main contribution to the heat conduction of cabin hulls is defined by insulations and air. A detailed model of air gaps inside doors and ceilings is also possible to create with HumanComfort library (see Fig. 3).

Typical values for materials found in automotive cabins are listed in the Tab. 1 below.

Tab. 1 Material thermal property data

\begin{tabular}{lccc}
\hline Material & $\begin{array}{c}\rho \\
{\left[\mathrm{kg} / \mathrm{m}^{3}\right]}\end{array}$ & $\begin{array}{c}\lambda \\
{[\mathrm{W} /(\mathrm{m} \cdot \mathrm{K})]}\end{array}$ & $\begin{array}{c}\mathrm{c} \\
{[\mathrm{J} /(\mathrm{kg} \cdot \mathrm{K})]}\end{array}$ \\
\hline Tin (Steel) & 7800 & 58 & 480 \\
Insulation & 60 & 0.047 & 1680 \\
Carpet & 750 & 0.072 & 1000 \\
Glass & 2500 & 1 & 800 \\
Plastic & 1300 & 0.21 & 1470 \\
\hline
\end{tabular}

Window partitions are characterized by further parameters for emissivity and absorption of irradiance. Those parameters are usually well known although there might be also manufacturers who provide the solar heat gain coefficient (SHGC) instead. This factor does not distinguish between the temporary internal and external heat transfer coefficients which is a problem, when boundary conditions change. Thus, the experimental heat transfer coefficients have to be known in addition.

Typical values for short wave transmission factors $\tau_{\mathrm{sw}}$, short wave absorption factors $\alpha_{\mathrm{sw}}$ and long wave emission factors $\varepsilon_{\mathrm{lw}}$ of different single pane glasses are given in Tab. 2 (refer also to [8]). Those factors have a considerable impact on the heat load of a cabin.

Tab. 2 Window irradiance transmission, absorption and emission data

\begin{tabular}{lccc}
\hline Glass & $\tau_{\mathrm{sw}}$ & $\alpha_{\mathrm{sw}}$ & $\varepsilon_{\mathrm{lw}}$ \\
& {$[-]$} & {$[-]$} & {$[-]$} \\
\hline Clear & 0.84 & 0.08 & 0.91 \\
Green & 0.60 & 0.32 & 0.80 \\
IR & 0.50 & 0.41 & 0.80 \\
\hline
\end{tabular}

Such factors are also required for opaque internal and external surfaces as part of the cabin hull (see Tab. 3).
Tab. 3 Hull surface irradiance factors

\begin{tabular}{lcc}
\hline Hull & $\alpha_{\mathrm{sw}}$ & $\varepsilon_{\mathrm{lw}}$ \\
& {$[-]$} & {$[-]$} \\
\hline White & 0.30 & 0.85 \\
Dark blue & 0.80 & 0.90 \\
Black & 0.99 & 0.98 \\
Internal & 0.80 & 0.80 \\
\hline
\end{tabular}

\subsection{Boundary Conditions for Simulation}

Measurements from an experimental facility were supplied for two experiments at different boundary conditions:

1. Passive heat up and pull down scenario at $45^{\circ} \mathrm{C}$ ambient temperature and $1000 \mathrm{~W} / \mathrm{m}^{2}$ vertical, direct irradiation (summer), refer to Fig. 5 to 7

2. Heat up scenario at $-20^{\circ} \mathrm{C}$ ambient temperature (winter), refer to Fig. 8 to 10

The passive heat up and active pull down scenario starts with a passive preconditioning of the cabin. This is achieved by radiant heaters installed above the cabin. After one hour of heating the driver enters the car and starts the engine as well as the AC system. The driving cycle started after the preconditioning consists of three speed intervals: $1.32 \mathrm{~km} / \mathrm{h}$, 2. $0 \mathrm{~km} / \mathrm{h}$ (idle), $3.64 \mathrm{~km} / \mathrm{h}$. The driver introduces a sensible heat flow rate of at least $80 \mathrm{~W}$ as well as a moisture input of $6.5 \mathrm{~g} / \mathrm{h}$.

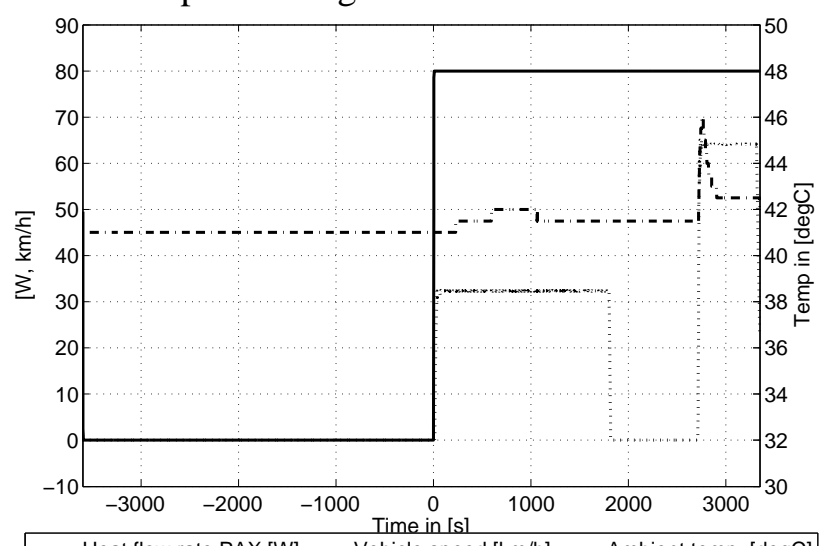

- Heat flow rate PAX [W] ....... Vehicle speed [km/h] . . - . Ambient temp. [degC]

Fig. 5 Boundary conditions for passive heat up and active pull down simulation - Speed, ambient temperature and heat flow rate of passengers

It is important to understand that the car is located in an artificial experimental setup and will not move during all driving cycles. Instead, the air velocity of the surrounding air is changed accordingly. During the passive heat up the vehicle is actually exposed to a small air flux to prevent overheating on some ex- 
ternal surfaces. The exact wind speed is unfortunately not known but was assumed to be small. Another large impact on the car's heat balance is imposed by walls of the experimental facility which emit long wave radiation.

The air distribution system of the car is equipped with six measurement sensors for air temperature:

- (Front) Face Center

- (Front) Face Side (Left \& Right)

- Face Rear

- Foot Front

- Foot Rear

- Defrost

The mass flow rate of air is recalculated from the fan characteristic assuming a certain fixed distribution between the outlets.

During pull down in summer only the upper outlets are used and foot outlets are closed. The total mass flow rate of air sums up to constant $550 \mathrm{~kg} / \mathrm{h}$. Note that the air temperature measured during passive heat up is due to heat dissipation only.

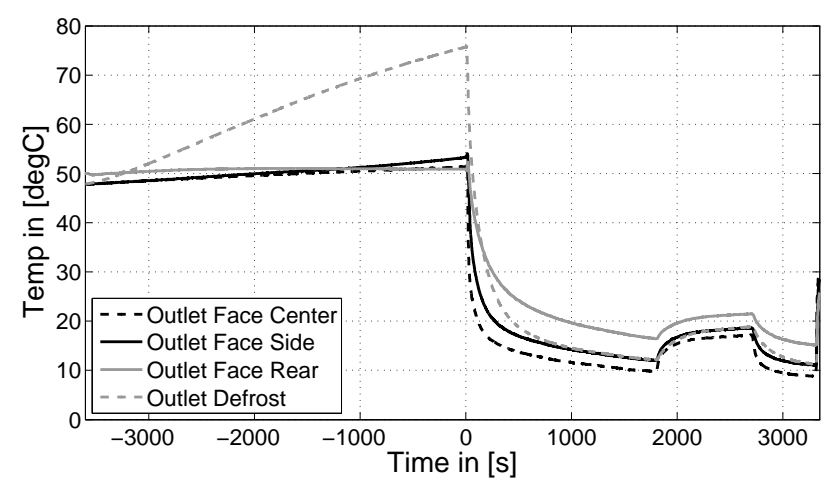

Fig. 6 Outlet air temperatures for passive heat up and active pull down - no outflow for time less than 0 sec.

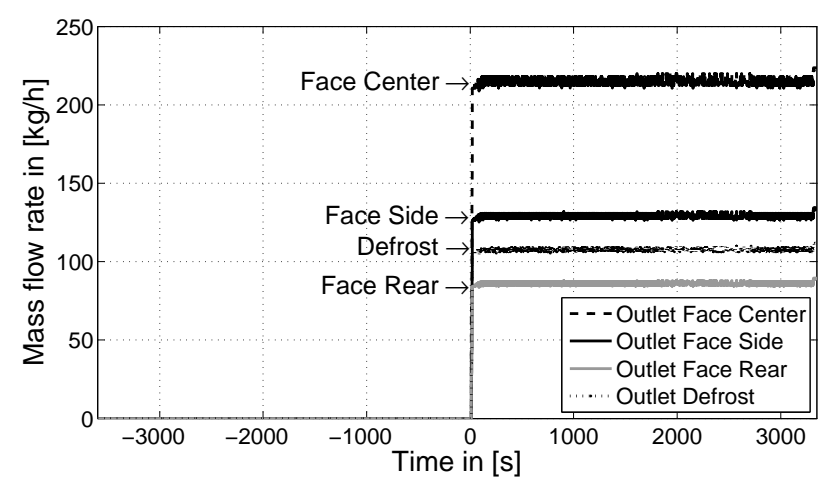

Fig. 7 Outlet mass flow rate of air distribution system for passive heat up and active pull down
In case of the winter scenario a preconditioning of the cabin model is not required, since all partitions are having nearly the same temperature slightly above $-20^{\circ} \mathrm{C}$. Here, the driving cycle is simpler: $1.50 \mathrm{~km} / \mathrm{h}, 2.0 \mathrm{~km} / \mathrm{h}$ (idle).

Comparing Fig. 9 with Fig. 10 reveals that the air temperature of the rear face outlet is nearly constant until $500 \mathrm{sec}$ although a mass flow rate is shown by the measurement. This deviation from a plausible physical behavior indicates that the Face Rear Outlet is just opened at that time point in order to prevent passenger's exposition to cold draft. It is assumed that the total mass flow rate is correct though. Nevertheless, in order to create correct energy balances it was decided to consider just those outlets which had a temperature larger than $-19^{\circ} \mathrm{C}$. The total mass flow was evenly distributed across the remaining open outlets.

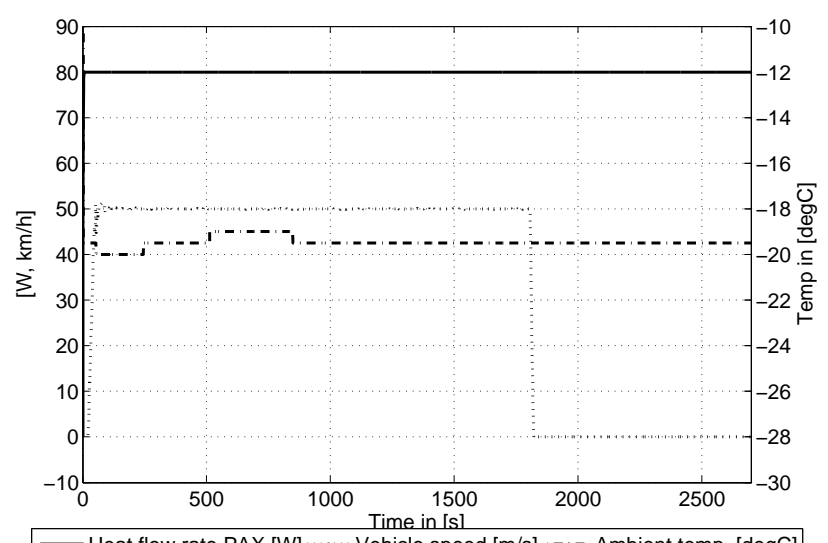

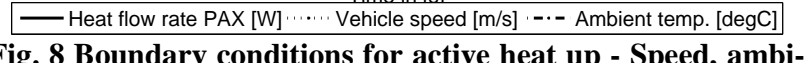
ent temperature and heat flow rate of passengers

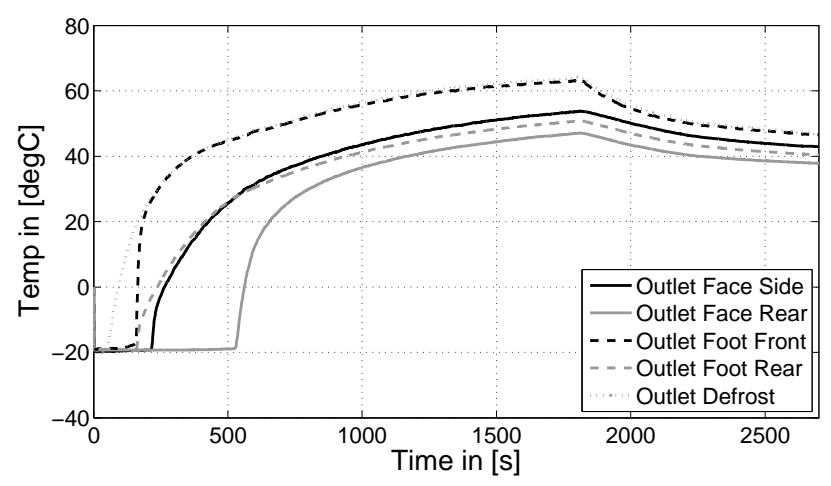

Fig. 9 Outlet air temperatures for active heat up 


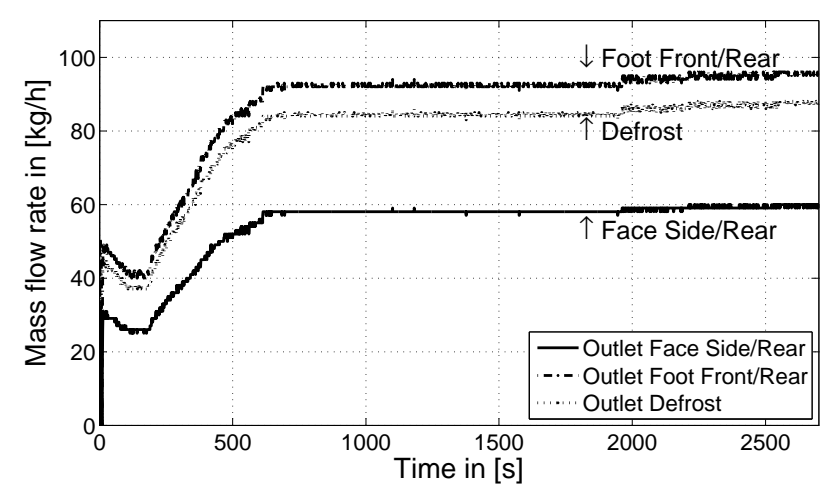

Fig. 10 Outlet mass flow rate of air distribution system for active heat up

\section{Calibration Process of the Cabin Model}

\subsection{Comments on Planning Measurements for Calibrating Cabin Models}

There are some pitfalls in using cabin temperature measurements for calibration of cabin models. A general problem is to define correct boundary conditions of the cabin. Especially, the air temperature measurement has to provide at least all temperatures at the virtual outlets of the air distribution system as well as the exhaust/return air inlet since a considerable heat transfer is taking place in the usually not insulated air channels. The effect of temperature gains on the heat load in recirculation mode can be up to $20 \%$.

For multi-volume approaches it is helpful to know approximately the actual mass flow distribution by the air distribution system, since it can become laborious to determine active air outlets at each time point (see section 2.1).

\subsection{Calibration Results}

The calibration process of the HumanComfort model is required in order to determine important, unknown parameters that have a large impact on the thermal behavior of the cabin. Those are usually:

- Internal and external heat transfer coefficients
- Emission and absorption factors of internal and external surfaces (in this case known)

- The average number of reflections between internal surfaces until the remaining rest of a portion of external short wave irradiance is reflected to ambience (decay of short wave irradiance)

The influence of the cabin hull (ignoring windows) is small on the static heat transfer. Nevertheless the cabin hull walls should not be ignored during transient simulations due to their large heat capacity which causes high heat flow rates to the cabin air in air conditioning or heating mode.

In this study it was possible to calibrate convective heat transfer and heat transfer due to solar irradiation separately since in the winter case simulated on a test facility solar irradiation was not present. Thus, a two step calibration is performed starting with the assessment of the heat transfer coefficients. Afterwards, a calibration of the radiation model's parameters was carried out. In order to simplify the calibration process it was decided to work with average heat transfer parameters. Since there is in all cases a strong variation of air velocity present, a generic heat transfer model in the following form was used:

$$
\alpha_{\text {avg ext }}=\alpha_{\text {const ext }}+\frac{\alpha_{\text {nom ext }}}{\underbrace{c_{\text {nomext }}}_{\gamma_{\text {ext }}}} \cdot c_{\text {ext }}
$$

and

$$
\alpha_{\text {avg int }}=\alpha_{\text {const int }}+\frac{\alpha_{\text {nomint }}}{\underbrace{c_{\text {nomint }}}_{\gamma_{\text {int }}}} \cdot c_{\text {int }}
$$

The parameters $\alpha_{\text {const }}$ and $\gamma$ were fitted by using the XRG's ModelOptimizer optimization tool to obtain a minimum integral deviation from the average cabin air temperature. ModelOptimizer offers both global and local optimization schemes so that a global optimum can be found.

The external air velocity $c_{\text {ext }}$ is equal to the vehicle speed while the internal air velocity $\mathrm{c}_{\text {int }}$ shows a huge variation across the cabin. In order to simplify the calibration process an average velocity in an arbitrary cross section of the cabin has been chosen: 


$$
c_{\text {int }}=\frac{\dot{m}_{\text {in }}}{\rho A_{\text {cross }}}
$$

The calibration process yielded different values for both measurements due to smaller uncertainties. In the winter case external heat transfer coefficients turned out to be lower than in the passive heat up and pull down case. A very small deviation for both cases was found with the same parameters:

- $\alpha_{\text {const }}=7.0 \quad\left[\mathrm{~W} /\left(\mathrm{m}^{2} . \mathrm{K}\right)\right]$ for internal and external heat transfer,

- $\gamma_{\text {ext }}=0.5 \quad\left[\mathrm{~J} /\left(\mathrm{m}^{3} \cdot \mathrm{K}\right)\right]$,

- $\gamma_{\text {int }}=40.0\left[\mathrm{~J} /\left(\mathrm{m}^{3} \cdot \mathrm{K}\right)\right]$,

- Integer number of reflections for short wave irradiance in top node: 1 ,

- Integer number of reflections in bottom node: 3 .

The number of reflections was calibrated by comparison of heat transfer coefficients for different settings in the heat up and pull down case.

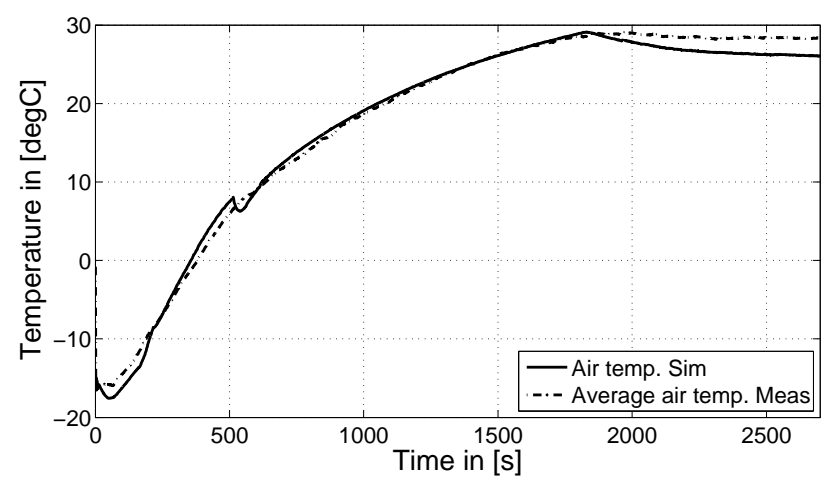

Fig. 11 Calibration result for winter case - comparison of average air temperature

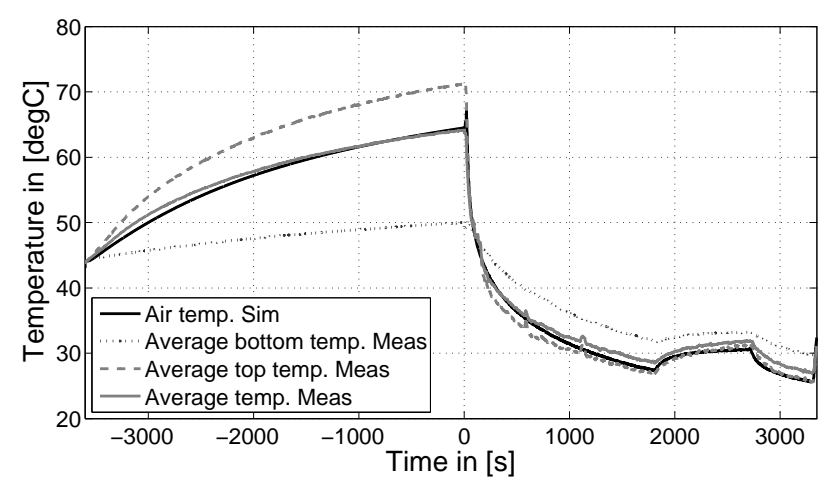

Fig. 12 Calibration result for passive heat up and active pull down - comparison of average air temperature
In Fig. 11 and Fig. 12 the result for the average air temperature inside the cabin is shown. The integral deviation of the squared temperature difference is $3790\left[\mathrm{~K}^{2} \mathrm{~s}\right]$ in the heat up case and $6140\left[\mathrm{~K}^{2} \mathrm{~s}\right]$ in the passive heat up and active pull down case, which corresponds to an average deviation of approx. 0.9 to $1.2 \mathrm{~K}$. During heat up the temperature slope is captured in a good way. For both cases there are higher deviations present at the end of each cycle. In the heat up case the temperature deviation starts to increase at $1800 \mathrm{sec}$ when the car speed is decreased to $0 \mathrm{~km} / \mathrm{h}$. It was not possible to find heat transfer coefficients that could display the measured behavior though. Thus, this deviation could also be due to wrong assumptions or interpretations of the measurements. In the passive heat up and pull down case a static deviation of approximately $2 \mathrm{~K}$ is present in always every speed interval when the AC is on. An exclusive calibration for this case yielded better results with higher heat transfer coefficients. But since both cases required a small deviation average heat transfer coefficients were chosen. Nevertheless, the static temperature deviation is not larger than $1.5 \mathrm{~K}$, again.

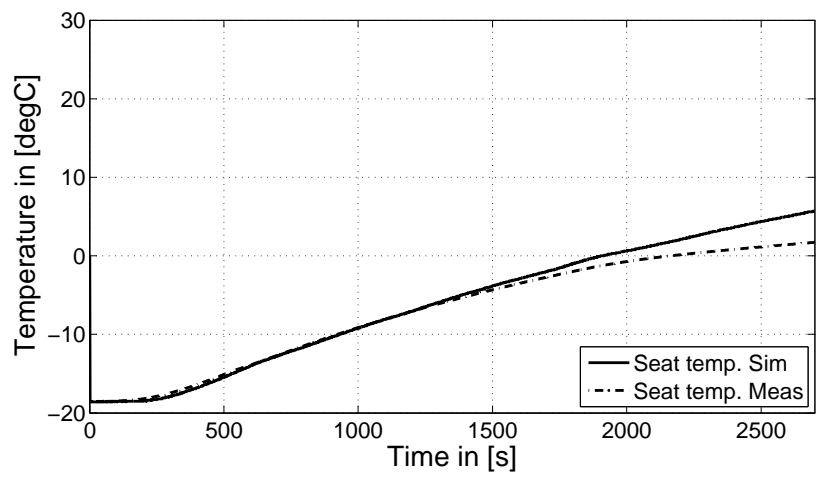

Fig. 13 Seat temperature for the active heat up case

An interesting auxiliary variable (which was not calibrated) is the seat temperature provided for both measurements (refer to Fig. 13 and 14). The plot reveals that the temperature slope shows in general a comparable plot. It has to be stated that the position of the measurement sensor inside the seat was not known. During the calibration it was found that the internal heat transfer coefficient had a large impact on both plots. The coefficients that were determined at the end of the calibration process yielded a good solution which indicates a successful calibration again. 


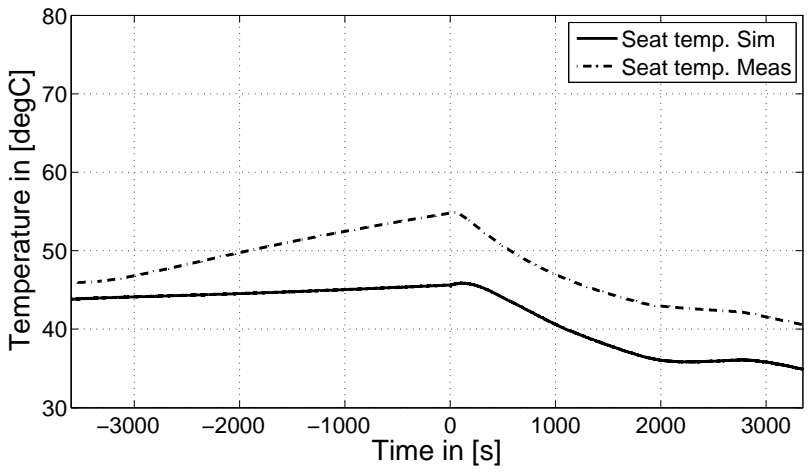

Fig. 14 Seat temperature for the passive heat up and active pull down case

\section{Conclusions}

The models in XRG's HumanComfort library was successfully used for thermal automotive cabin simulations. The models consider all kinds of thermal heat transfer which is mandatory for using the model in different applications. Due to its modular design the user can easily and quickly exchange components and modify the layout for his needs. Coupling to other Modelica libraries, e.g. for modeling air distribution systems or air conditioning systems is possible since Modelica.Fluid compatible interfaces were used. The modeling process for a single car can be done within one day including parameterization with data provided.

This article was aiming to present a way to calibrate an efficient system level model such that it achieves a comparable accuracy as for more complex approaches (refer to [4]) with much less effort. The time to model the cabin and calibrate it takes approximately two weeks or even less when starting from a template. Furthermore, it was shown that a calibration has to take at least two different cases into account: one case with and one without external short wave irradiance (winter and summer case). The measurements should include a broad range of vehicle speeds and inlet air low rates. With regard to the last point the distribution and amount of air has to be identified as accurate as possible.

\section{Acknowledgements}

The author would like to thank Denso Automotive Deutschland $\mathrm{GmbH}$ for the kind provision of measurement data used in this study.

\section{References}

[1] Michaelsen B., Eiden J.: HumanComfort in Buildings and Mobile Applications: In proceedings of the $7^{\text {th }}$ Modelica Conference, Como, Italy, 2009, pp. 403-412.

[2] Pfafferott T., Schmitz G.: Modelling and transient simulation of $\mathrm{CO} 2$-refrigeration systems with Modelica, International Journal of Refrigeration, Elsevier, Volume 27, Issue 1, 2004, pp. 42-52.

[3] Modelon AB, AirConditioning Library version 1.8, Users Guide, Modelon $\mathrm{AB}$, Sweden, Oct. 2010.

[4] Neacsu C.-A., Ivanescu M., Tabacu I.: The influence of the solar radiation on the interior temperature of the car, http://www.theseusfe.com/downloads, 2009.

[5] Kaiser C., Försterling S., Tegethoff W., Köhler J.: Untersuchungen von Regelstrategien für die Omnibusklimatisierung mit Hilfe einer Gesamtfahrzeugsimulation, In proceedings of ASIM GI Workshop, Wolfenbüttel (Germany), Feb. 2012.

[6] Baumgart R., Tenberge P., Urbaneck T.: Senkung des Kraftstoffverbrauchs durch Optimierung der Klimaanlage: In proceedings of $14^{\text {th }}$ international congress and exhibition SIMVEC - Numerical Analysis and Simulation in Vehicle Engineering 2008, BadenBaden (Germany), 2008.

[7] Mezrhab A., Bouzidi M.: Computation of thermal comfort inside a passenger car compartment, Journal of Applied Thermal Engineering, Elsevier, Volume 26, 2006, pp. 1697-1704.

[8] Grossmann, H.: PKW-Klimatisierung, Springer Verlag, Berlin, 2010. 
